\section{Questioning the ethics of John Bohannon's hoaxes and stings in the context of science publishing}

KOME - An International Journal of Pure Communication Inquiry Volume 4 Issue 1, p. 84-88. (C) The Author(s) 2016 Reprints and Permission: kome@komejournal.com

Published by the Hungarian Communication Studies Association DOI: 10.17646/KOME.2016.16

\author{
Jaime A. Teixeira da Silva ${ }^{1}$ and Aceil Al-Khatib ${ }^{2}$ \\ ${ }^{1}$ Retired researcher, Japan \\ ${ }^{2}$ Jordan University of Science and Technology, Jordan
}

In recent years, investigative journalism has been widely used by the media to obtain news of importance to the public such as headlines about exposing corruption, revealing wrongdoers, and shedding light on hidden actions (Aucoin, 2014). In their attempts to deeply research and reveal hidden news to the public, journalists may employ tactics used by law enforcement authorities such as undercover journalism or sting operations (Kroeger, 2012). For the purpose of this paper we define sting operations "as any effort by the authorities to encourage wrongdoing, with the intention of punishing the offenses that result" (Hay, 2005). While some may regard the use of sting operations by journalists to be a great and powerful tool in exposing wrongdoers, many disagree because it "would send the wrong message to young reporters everywhere that it was all right to lie to get a story, to pretend to be not a reporter but some one you were not" (Goldstein, 2012). Although sting operations are most commonly used by law enforcement authorities, they are also used by private and public organization and even in divorce cases (Hay, 2005), and more recently, in science publishing. In this opinion paper we describe recent sting operations in science publishing and explain the potential breach of ethics that may be associated with the deception employed in running such operations.

In 2013, Dr. John Bohannon, an investigative journalist, made headlines with a paper published in Science (Bohannon, 2013) based on a sting that involved the submission of hundreds of false manuscripts with purposefully manipulated and/or fabricated data, false authors and false institutions. As Bohannon himself states, as one example: "Ocorrafoo Cobange does not exist, nor does the Wassee Institute of Medicine." All manuscripts were made with false declarations upon submission regarding originality, and examination of the emails revealed misleading statements until the manuscript was either accepted, or rejected. All of these submissions were made with a single intention: to show the failure of peer review in so-called "predatory" open access (POA) journals. Bohannon's widely acclaimed results 
fortified the notion that the open access movement has become corrupted to some extent as a result of lax, false or non-existent peer review. Incidentally, this is also a problem in traditional publishers (Teixeira da Silva and Dobránszki, 2015). Despite Bohannon's findings, a basal premise of the Bohannon "sting" operation was widely ignored, and rarely acknowledged, namely that some or all of the requirements for submission of a manuscript to these POA journals were not met, and were either false or non-existent. For example, one of the clauses of the guidelines for submission to Public Health Research (PHR), a journal published by Scientific \& Academic Publishing, and a journal stung by Bohannon, is that "The submission has not been previously published, nor is it before another journal for consideration" (PHR, 2015). This core publishing ethics clause was ignored by Bohannon in this and most likely all of the several hundreds of journals he "spoofed".

Shocked by this glaring violation of the guidelines of submission of manuscripts to scholarly journals, one would have expected entities involved in research communications, as well as the OA community, to issue a clear expression of concern, opinion or guidelines regarding the ethics of sting operations in scholarly publications. Sadly, this has not been the case, even almost more than three years after the first Bohannon "sting". Review upon review of Bohannon's sting primarily piled praise (e.g., OASPA 2013a), and most criticism has been lukewarm (e.g., as "dubious" by Eve in Buckland et al., 2013, p. 2), subtle (e.g., as "an iota of good" by Gardy in Buckland et al., 2013; p. 4), or restricted almost entirely to the lack of a suitable control group (e.g., as "a significant own goal" by Science, as referred to by Steel in Buckland et al., 2013, p. 3), or critical of a misguided "sting" (e.g., as "the problem is that he didn't sting anywhere near all the journals desperately needing to be stung" by Salo in Buckland et al., 2013, p. 6). However, these and other papers have failed to call out or question the overriding gaps in publishing ethics in the Bohannon stings. Moreover, no apology or clarification was ever offered to the victims of this sting, namely the spoofed journals, their editors, or their publishers. Bohannon in essence wasted their time and human resources, and finally their patience in dealing with fake papers and fake submissions. In order for the reader to better appreciate the nature of the ethics of those who blatantly violate the ethics of the submission process in search of a higher morale, one need only imagine if a researcher (or regular scientist) had submitted the same false papers with false names, false emails and false institutional addresses to a journal published by a mainstream oligopolic publisher like Elsevier Ltd., Wiley-Blackwell, Taylor and Francis / Informa, or SpringerNature (Larivière et al., 2015). It is not difficult to imagine that such an action would have merited severe punishment such as a publishing ban. Despite this, the most prolific and overwhelmingly supportive opinion that has resulted from Bohannon's sting has been a praise of his actions and a severe criticism of the POA journals he stung (e.g., OASPA 2013a).

Once again, and more recently, another sting has come under additional scrutiny. As before, using a masqueraded name, a false institution and an email address that appeared to be valid, Bohannon et al. (2015) submitted a paper to the International Archives of Medicine (IAM) to apparently help a television reporter demonstrate "just how easy it is to turn bad science into the big headlines behind diet fads", proudly advertising that he "fooled millions into thinking chocolate helps weight loss" on the io9.com blog (Bohannon, 2015). In addition to most likely violating the guidelines of submission to IAM, Bohannon et al. used p-hacking, "which occurs when researchers collect or select data or statistical analyses until nonsignificant results become significant" (Head et al., 2015), with the objective of showing the beneficial effects of chocolate with a high content of cocoa on weight loss, as demonstrated by "significant" data, and it is for this reason that the paper was retracted (McCook, 2015; Oransky, 2015), as confirmed by the then editor-in-chief of IAM, Prof. Manuel Menendez. 
Why then, if a similar false and deceptive methodology was used in both the IAM and Science papers, has the 2013 Science paper not been retracted, or, at minimum, why has an expression of concern not been issued, especially with clearly proven "flaws and weaknesses" (a comment by Steel in Buckland et al., 2013)? This lack of accountability by Science is stated by Crawford (2014) in his detailed critique of Bohannon's 2013 Science paper: "Science has to take at least as much responsibility for the quality of this study as it does for, say, articles about arsenic-based life."

The outcome of several stings has shown unequivocal results about false and imperfect peer review in POA journals leading to some positive ramifications such as stricter journal quality control by the Directory of Open Access Journals (DOAJ), which removed 114 journals titles from its listing, although the DOAJ also recognized the ethical flaws of the Bohannon sting: "There is one final point that DOAJ would like to make, one that we feel may have been overlooked by the majority. To carry out his exercise, as well as cooking up fake scientific papers and persistently pushing journals into accepting them, Bohannon also needed to create fake authors. We are wondering why he felt that the paper's authors had to have names hailing from the African continent?" Curiously, that document has "mysteriously" disappeared from the DOAJ public archives. Furthermore, the sting has evoked greater awareness and heightened discussion about the impact of POA journals on science publishing. There have even been more serious ramifications for those POA journals that were spoofed, for example, by OASPA (OASPA 2013b): "we are therefore reluctantly terminating the memberships of Hikari and Dove Medical Press. We have indicated that we will be willing to reconsider a membership application but not before 12 months have elapsed." However, the method by which a sting is conducted and the publishing ethics that are violated in order to achieve an objective, or to make a statement, also needs to be focused, and rebuked where and when necessary. It does not seem right to hold scientists and regular authors to one set of publishing values, and to hold investigative journalists to a separate set of values. As far as the Bohannon "stings" or "hoaxes" go, not conforming to current professional standards and ethical conduct during the submission of a manuscript (Bastian, 2015; Haider and Åström, 2016) could set a dangerous precedent for copy-cat stings and hoaxes by those who believe that Bohannon's actions were praiseworthy.

This is not to say that the use of stings is unjustified. Clearly, a sting operation can sometimes be the only tool to collect information or evidence on a matter of public interest, as was shown by a fairly recent sting that was orchestrated by undercover Science reporters. Those undercover reporters posed as graduate students investigating "corrupt publishing practices" by "paper selling agencies" which sell authorship for scientific articles (Hvistendahl, 2013) in China. Such an investigation, in our opinion, is justified, as it was perhaps the only tool - and a last resort - to shedding light on companies that provide brokered services to authors, and because the scientific community has a compelling interest in learning about such corrupt business practices supporting science publications. While sting operations can sometimes be the only way to present solid evidence on a topic of strong public interest, we believe that in scientific research and publications, such stings should be discouraged or at least a safeguarding policy should be implemented to protect the integrity of scientific research. This is because, under the claim of sting operations, fraudulent research and questionable practices can be maliciously used to advance the interests of private entities, or even violate the rights of any of those involved in scientific, academic and medical research.

Finally, a PubPeer page for open discussion on the Bohannon sting is now available. 


\section{References}

Aucoin, J. L. (2014) Investigative reporting. Oxford Bibliographies Online CrossRef

Bastian, H. (2015) Tricked: the ethical slipperiness of hoaxes.

http://blogs.plos.org/absolutely-maybe/2015/05/31/tricked-the-ethical-slipperiness-ofhoaxes (last accessed: 6 May, 2016)

Bohannon, J. (2013) Who's afraid of peer review? Science 342 (6154): 60-65. CrossRef

Bohannon, J. (2015) I fooled millions into thinking chocolate helps weight loss. Here's how. Gizmodo http://io9.com/i-fooled-millions-into-thinking-chocolate-helps-weight1707251800 (last accessed: 6 May, 2016)

Bohannon, J., Koch, D., Homm P., Driehaus, A. (2015) Chocolate with high cocoa content as a weight-loss accelerator. International Archives of Medicine 8 (55), $8 \mathrm{pp}$ (retracted). Archived at Wikimedia:

https://upload.wikimedia.org/wikipedia/commons/3/39/Chocolate_with_high_Cocoa_ content_as_a_weight-loss_accelerator.pdf (last accessed: 6 May, 2016)

Buckland, A, Eve, M, Steel, G, Gardy, J, Salo, D. (2013). On the mark? Responses to a sting. Journal of Librarianship and Scholarly Communication 2(1): eP1116. CrossRef

Crawford, W. (2014). Ethics and access 2: the so-called sting. Cites \& Insights 14(5): 1-20.

Goldstein, T. (2012). The brief against deception in reporting. Journal of Magazine \& New Media Research 13(1): 1-3.

Haider, J. and Åström, F. (2016). Dimensions of trust in scholarly communication: Problematizing peer review in the aftermath of John Bohannon's "Sting" in Science. Journal of the Association for Information Science and Technology. CrossRef

Hay, B. (2005) Sting operations, undercover agents, and entrapment. Missouri Law Review 70(2): 387-431.

Head, M. L., Holman, L., Lanfear, R., Kahn, A. T., \& Jennions, M. D. (2015) The extent and consequences of p-hacking in science. PLoS Biology 13(3), e1002106. CrossRef

Hvistendahl, M. (2013) China's publication bazaar. Science 342(6162):1035-1039. CrossRef

Kroeger B. (2012) Why surreptitiousness works. Journal of Magazine \& New Media Research 13(1): 1-3.

Larivière V, Haustein S, Mongeon $\mathrm{P}$ (2015) The oligopoly of academic publishers in the digital era. PLoS ONE 10(6): e0127502. $\underline{\text { CrossRef }}$

McCook, A. (2015) Chocolate-diet study publisher claims paper was actually rejected, only live "for some hours." Email, however, says... Retraction Watch [blog] http://retractionwatch.com/2015/05/28/chocolate-diet-study-publisher-claims-paperwas-actually-rejected-only-live-for-some-hours-email-however-says/ (last accessed: 6 May, 2016)

OASPA (Open Access Scholarly Publishers Association) (2013a) OASPA's response to the recent article in Science entitled "Who's Afraid of Peer Review?" http://oaspa.org/response-to-the-recent-article-in-science/ (last accessed: 6 May, 2016)

OASPA (2013b) OASPA's second statement following the article in Science entitled "Who's 
Afraid of Peer Review?" http://oaspa.org/oaspas-second-statement-following-thearticle-in-science-entitled-whos-afraid-of-peer-review/ (last accessed: 6 May, 2016)

Oransky, I. (2015) Should the chocolate-diet sting study be retracted? And why the coverage doesn't surprise a news watchdog. Retraction Watch [blog] http://retractionwatch.com/2015/05/28/should-the-chocolate-diet-sting-study-beretracted-and-why-the-coverage-doesnt-surprise-a-news-watchdog/ (last accessed: 6 May, 2016)

PHR (Public Health Research) Author guidelines. http://www.sapub.org/journal/authorguidelines.aspx?journalid=1068 (last accessed: 6 May, 2016)

Teixeira da Silva JA, Dobránszki J. (2015) Problems with traditional science publishing and finding a wider niche for post-publication peer review. Accountability in Research: Policies and Quality Assurance 22(1): 22-40. CrossRef

Van Noorden, R. (2014) Publicly questioned papers more likely to be retracted. Nature CrossRef 